\title{
Coping over time: the parents of children with autism
}

\author{
D. E. Gray \\ School of Social Science, University of New England, Armidale, New South Wales, Australia
}

\begin{abstract}
Background Although coping with autism has been examined in a number of papers, virtually no research exists on how families cope over time. This paper reports the results of a longitudinal study of parents coping with autism over a period of approximately a decade.

Methods The research method for the study was based on ethnographic methods that emphasized indepth interviews and participant observation. The sample for this study consisted of 28 parents (I9 mothers and nine fathers) of children with autism. The instrument for the interviews consisted of questions concerning: the child's medical history and referral experience, the child's present symptomatology, the effects of the child's problems on the parent's well-being, the effects of autism on the family's social life, parental coping strategies, illness conceptualization and the parents' expectations for the future.

Results and conclusions Coping strategies changed from the time of the initial study, as fewer parents coped through reliance on service providers, family support, social withdrawal and individualism and relatively more parents coped through their religious faith and other emotion-focused strategies. The results tentatively support previous research on coping that indicates that aging is linked to the use of more emotion-focused coping strategies.
\end{abstract}

Correspondence: Dr David E. Gray, School of Social Science, University of New England, Armidale, New South Wales, Australia 235I (e-mail: dgray@pobox.une.edu.au).
Keywords autism, coping, family

\section{Introduction}

As a challenge to the family, autism must rank among the most stressful of childhood developmental disabilities. Problems with communication, emotional expression and antisocial behaviours, all combined to place tremendous stress on the families of children with autism.

Despite these problems, families do cope with autism and often cope successfully (Bristol I984; Marcus et al. 1997). Nevertheless, the research on autism and family coping that does exist is crosssectional in nature, and, consequently, relatively little is known about how the coping activities of these families change over time. This purpose of this paper is to provide information on this subject by presenting the results of a qualitative, longitudinal study of family coping and autism.

A moderate amount of cross-sectional research exists that looks at how families cope with autism at particular phases of the child's development (Marcus I977; Bristol I984; Bristol I987; Gray I994; Hastings et al. 2005). This research has been of two main types. The first has used quantitative methods and focused on the factors that serve to ameliorate the stressful effects of the disorder (Bristol 1984; Bristol I987; Bristol et al. I988; Milgram \& Atzil I988; Gray \& Holden I992; Hastings et al. 2005). Among the various factors that are significantly related to various 
forms of parental distress and adjustment are the sex of the parent (Bristol et al. 1988; Milgram \& Atzil I988; Gray \& Holden I992) degree and type of social support (Bristol I984; Bristol I987; Bristol et al. I988; Milgram \& Atzil I988; Gray \& Holden I992), additional life stresses (Bristol I987), age of the child (Bristol I987; Gray \& Holden I992; Hastings et al. 2005) and coping activities (Bristol I984; Bristol I987; Hastings et al. 2005).

The second type of research on coping and autism has been qualitative in its methodological approach and emphasized either the nature of the families problems (Marcus I977; DeMeyer I979; Marcus et al. 1997) or the patterns of coping that parents employ to cope with their child's autism (Marcus I977; Gray 1994; Gray 2003). This research indicates that parents use a variety of coping strategies to deal with their child's autism including support from family and friends (Marcus 1977; Gray 1994), the use of service providers (DeMeyer I979; Gray I994), advocacy and support groups (DeMeyer I979) and religion (Gray 1994).

Previous research has provided valuable information about coping with autism. However, little is known about how coping with autism changes over time. There is, however, a significant amount of research that deals with general coping over the life course (Aldwin I99I; Thoits 1995) and it indicates that the coping activities of individuals change over time (Lazarus I996). In particular, research indicates that there is a general tendency for young adults to use more problem-focused coping strategies and middle-aged adults to use emotion-focused coping strategies (Lazarus 1996). The former refers to coping with the situation by changing the nature of the problem and the latter refers to coping that distracts the attention of the individual affected by a stressful situation. Included in this latter category of coping would be such activities as expressing feelings, praying, withdrawal, etc. (Lazarus 1996).

These findings suggest that coping with autism may also change over time. Previous research has reported that parents of young children with autism often had expectations that their child would make substantial progress towards normality as they aged (Gray 1994). However, the medical literature on autism does not support this optimism. Accordingly, it is reasonable to hypothesize that longitudinal research may find a shift to more emotion-focused coping strategies now that the children are older and the progress that their parents hoped for has not eventuated. The purpose of this paper is to provide information on this issue by examining how the coping strategies of a sample of parents of children with autism have changed over time.

\section{Method}

This research is a qualitative longitudinal study of the social experiences of families of children with autism. The research method for the study was based on ethnographic methods that emphasized in-depth interviews and participant observation.

\section{Sample}

In the initial study, which was conducted between I988 and I990, 77 parents with children presently enrolled at a treatment centre for autism were asked to participate in the project. A total of 50 parents agreed to do so; however, time and resource constraints limited the sample to 35 parents (25 mothers and Io fathers representing 26 families) living in the Brisbane region. In the follow-up study, which was conducted 8-Io years after the initial one, a total of 3 I of the 35 parents from the previous study were asked to participate and 28 (I9 mothers and nine fathers representing 20 families) agreed to do so. Those parents excluded from the longitudinal study had either moved out of the district or had been interviewed by another researcher and were considered to be inappropriate for present project.

The individuals with autism in this study had been diagnosed at a treatment centre for autism that used DSM-III-R criteria. At the time of the initial interviews, their degree of symptomatology ranged from mild to severe with the majority of them experiencing moderate to severe degrees of impairment. They included both juveniles and young adults, with their ages ranging from 4 to I9 years and approximately three-quarters of them falling between the ages of 6 and 12 years. The number of individuals with autism in the initial study was 24 and included I 6 males and eight females. All of them were living at home except for two who had residential placements.

At the time of the follow-up study, the situations of the individuals with autism had changed consider- 
ably. In particular, none were attending the treatment centre where they had previously been enrolled. Instead, of the 20 individuals with autism included in the follow-up study (I3 males and seven females), eight were enrolled at a special school for children with disabilities, eight were receiving some form of community service support and two were receiving no services at all. Except for the two remaining individuals who had residential placements at the time of the initial research, all of them were still living with their families at the time of the follow-up study. Although the general behaviour of most of the affected individuals had become more orderly, all were still significantly disabled by their condition. Only one individual was attending a regular school and none of those who had finished with school were employed in regular jobs. The median age of the affected individuals at the time of the follow-up study was $\mathrm{I} 8$.

\section{Instrument}

The data for this study were collected through indepth semi-structured interviews. The interviews with the parents included questions concerning: (I) the child's medical history and referral experience; (2) the child's present symptomatology; (3) the effects of the child's problems on the parent's wellbeing; (4) the effects of autism on the family's social life; (5) parental coping strategies; (6) illness conceptualization; and (7) the parents' expectations for the future.

The concept of coping is one that has been used widely in qualitative studies of the experience of chronic illness. There is, however, considerable variation in the meaning of this concept as it is applied in specific studies (Bury I99I). Although there is no definitive consensus that has emerged to distinguish the various types of coping activities, there is a widespread acknowledgement that the concept may refer to a variety of behaviours designed to cope with a problem (Bury I99I; Thoits I995) whether they are successful or not (Lazarus I993). The coping question used in this study asked the parents to describe the most important overall factor in helping them cope with their child's autism. This general coping question approximates the type of measure used in most qualitative studies of coping with illness (Bury I99I).

\section{Analysis}

The data for this study were analysed through an interactive process commonly employed in naturalistic research (Erlandson et al. I993). The first step in the process involved the indexing and selective transcribing of interview material following the broad categories and sequence of the interview questions. In the second stage, the material was examined for identifiable themes in the parents' comments. Finally, the responses compared with the parents' comments from the first stage of the research to examine how their coping responses had varied over time.

\section{Results}

The results concerning parental coping are presented in Table I. One of the most striking differences between parental coping at the time of the previous research and now is that the parents cited far fewer coping strategies than they had previously. This may partially reflect the declining degree of emotional distress experienced by the parents, as most of them noted that their children had improved to the point where they were significantly easier to live with, even if they retained many autistic symptoms. Furthermore, at the time of the previous research, most of the children were still relatively young and their parents were still contending with both the disruption

Table I Coping strategies

\begin{tabular}{|c|c|c|}
\hline & $\begin{array}{l}\text { First } \\
\text { study }\end{array}$ & $\begin{array}{l}\text { Follow-up } \\
\text { study }\end{array}$ \\
\hline $\begin{array}{l}\text { Use of treatment services (includes the } \\
\text { use of the autistic centre, special } \\
\text { schools, respite care, private carers, } \\
\text { etc.) }\end{array}$ & 14 & 6 \\
\hline Family support & 14 & 4 \\
\hline Religion & 5 & 5 \\
\hline Social withdrawal & 7 & 0 \\
\hline $\begin{array}{l}\text { Individualism (includes employment, } \\
\text { recreation, organizational activities, } \\
\text { etc.) }\end{array}$ & 6 & 2 \\
\hline $\begin{array}{l}\text { Other (includes various philosophical } \\
\text { perspectives, emotional reactions, } \\
\text { domestic, routines, contact with } \\
\text { other parents, etc.) }\end{array}$ & 5 & 10 \\
\hline Total coping strategies cited by parents & 51 & 27 \\
\hline
\end{tabular}


caused by their child's poor living skills and their own psychological adaptation to their child's disability. Now, some years later, both the child's living skills and their parents' adaptation to the situation are significantly more advanced.

There were also significant changes in the types of coping strategies that were cited by the parents in the follow-up study. For example, the previous research found that the most popular coping strategies among the parents were the use of treatment services and support from members of their family. The use of treatment services was especially important, as most of the children were still young enough to need the sort of life skills training in which the treatment centre for autism specialized. Furthermore, the child's attendance at the centre also provided daily respite for the parents and the opportunity to make use of the counselling services provided by the staff social workers. The results of the follow-up study indicate that the use of treatment services has declined dramatically. The main reasons for this are that none of the children are now enrolled at the treatment centre for autism and most have finished their education in the state schools for children with disabilities that they went to after leaving the centre.

The withdrawal of their children from the centre was reflected in the parents' changing attitudes about the services provided there. Although most of the parents believed that their child had benefited from being at the centre, they were usually less complimentary about it than they had been previously, and a number were highly critical of the services they had received. Part of the reason for this was that the centre's client base had changed over the years. Instead of focusing on children with profound autism, the centre now enrolled more children with high functioning autism or Asperger's syndrome, a fact that upset some of the parents of the more severely affected children. As one father said:

I think they do good things, don't get me wrong, but they could do a lot more. I had fundamental problems with some of the things they were trying to do and I left ... there was a fundamental shift towards catering for those people [with Asperger's syndrome] ... and [people with] Asperger's syndrome to me are not the most needy.

In cases where parents still use treatment services as their main means of coping, the children have either found a residential placement or the parents are using private treatment services. However, the declining reliance on treatment providers may also reflect the absence of services for adolescents and adults with autism, which means that parents can no longer rely on treatment providers even if they want to. In the most severe cases, some parents believed that an institutional placement might still be possible. But even in these cases, there were doubts about the availability of appropriate services for severely affected adolescents and adults. As one mother of a violent teenage child said:

I can see us getting to a point in the next I5 years where we're not going to be able to fend off the attacks. And that she'll have to go somewhere and it would just kill me to think that she went somewhere, you know, really, really unfitting.

Support from other members of the family remained an important coping strategy for some parents in the follow-up study, and in these cases its importance was often expressed with considerable emotion. As one father said:

Of course the loyalty that my wife and I have toward each other. I think that's important and helps us cope. We share. I mean she tells me all about it and [we'll] sit down for half an hour and she'll tell me all about the problems or we'll deal with the problems together. I think that's the only way that you can do it.

Nevertheless, this coping strategy was not cited as often as it had been at the time of the initial research. There are a couple of possible reasons for this change. One possible explanation is that much of the support that was previously provided by family members was emotional in nature, and, as the level of emotional distress has declined, so has the need for the degree of support provided earlier.

Second, the decline in family support as a coping strategy may also reflect the habituation of many coping activities. In particular, there were several parents who had cited family support as one of their main coping strategies at the time of the initial research, but not at the follow-up, and yet noted their reliance on certain activities that required a significant degree of family cooperation. For example, one mother had previously cited family support as her main forms of coping, described the technique of close surveillance 
D. E. Gray - Coping over time

that was part of her present way of coping with her son's autism:

Even here [at home], I mean, if you notice for awhile that, 'Gee I haven't seen him for Io or I5 minutes', you just sort of quietly check what he's doing without sort of being too obvious about it. Cause chances are he's hacking into the plants or found some insects and [is] torturing them or something like that ... you've sort of gotta watch him ... I suppose we've sort of adapted our lives to him.

This close surveillance, which was observed by the author, was one that involved the whole family, including the family's younger children. Although it may not have been perceived as a form of family support by this parent, it could not have easily been accomplished without the other family members' participation. Furthermore, this was a type of activity that was common in many of the families in this study.

Although the number of parents citing religion as a coping strategy remained the same over time, its share of the proportion of all coping activities increased. In all but one of the cases where the parents reported religion as their main coping strategy in the follow-up study, the parents had previously cited the use of treatment services as their main means of coping. It is possible that this reflects both the declining importance of treatment services and an acceptance by the parents that their earlier expectations about their child's improvement will not be fulfilled. Under the circumstance, the parents may have found it more important to acknowledge the permanence of their child's disability and find a way of thinking about it that will put it into a meaningful perspective. As one mother said:

The most important thing is believing in God. And I'll have to say that because that is the only thing that has kept me sane and rational on the rails, I think, through all these years. Because I've not just had that problem. I've had major problems in my life with health, marriage break-up, finances, you know. I mean, I think I've just about had everything happen, so I would have to say that God has helped me just keep on the rails, keep it, keep it together.

Social withdrawal and individualism were both coping strategies that declined over time. This may have reflected the more orderly habits and improved public behaviours of the children as they aged, which allowed their parents to engage in more social activities and feel less need to distract themselves through other activities. However, these results may also reflect the parents' adjustment to raising an autistic child as much as an actual change in behaviour. For example, at the time of the initial study, the children were younger and their parents often were still adjusting to the social limitations placed on their activities by their child's disability. A decade later they may have been more accustomed to these limitations and less likely to see them as a deliberate coping strategy even if they still lived relatively isolated lives. As one mother commented:

He has matured a great deal ... [become] more controlled ... He has become quieter. We have longer periods of time when his behaviour ... is good. You have to say 'good', but he just lives his own little life doing his own things. He still likes his routines.

However, despite improvements in her son's behaviour, the same mother also described the social restrictions imposed on her family and described their lifestyle as 'reclusive'. In short, the difference between their social life at the time of the initial study and the follow-up may have had less to do with an increase in social activity than with becoming accustomed to these restrictions.

The final coping strategy was a residual category of various activities that were described as 'other'. This is the one category of coping that was reported more frequently at the time of the follow-up study than it was during the initial study. However, there was little consistency in the behaviours cited here as they involved a variety of philosophical attitudes, emotional responses and domestic activities. Nevertheless, several of the responses provided by the parents in this category involved emotion-focused coping strategies that were not found in the previous study. For example, several of parents cited their attachment to their child or an appreciation of his or her appreciating good qualities and achievements. As one mother said:

It would be part of [my daughter's] personality. She's got that bubbly nature. She's got a good nature and I think if [she] was normal, she'd have 
a very warm personality, and she'd have a real sense of humor because she displays that even when you see her by herself, and sometimes you just can't help sometimes but sort of laugh and just feel that delight in her, and I find that as much as we have those times of frustration, I mean, she still brings a lot of joy at the same time .. . That's the side that I focus on . . . because she has got that side . . . and that helps me get through.

\section{Discussion}

For the families in this study, the problems of parenting a child with autism, and their means of coping with it, have changed over time. The total number of coping strategies reported by parents declined and there was a general shift away from problem-focused towards emotion-focused means of coping. In particular, the reliance on service providers has declined and the relative importance of religion and other coping strategies such as an appreciation of their child's good qualities have increased.

The reasons for these changes may reflect both the changing problems of the children and the services currently available for their treatment. In the first case, most of the children have improved over time as they have become less disrupted and more orderly in their habits. As a consequence, family life has become more routinized and the parents experience lower levels of distress and use fewer coping strategies, or at least perceive themselves to be doing so. Nevertheless, all of the children are still significantly disabled and the previous hopes of their parents for a substantial recovery are now less tenable than at the time of the initial study. In the second case, the treatment services available for late adolescents and adults with autism are quite limited. At the time of the follow-up study, most of the children had finished with their education and treatment at the autistic centre and special schools and the services that were available varied significantly in terms of their quality and accessibility.

It is worth noting in this regard that one of the limitations of this study is the inability of the present data to determine which of these factors - the changing nature of the children's problems or the access to appropriate services - is the most important in affecting the changes in the parents' coping strategies.
Research using larger samples with more a extensive range of available services would be necessary to ascertain which factor had the most significant effect parental coping with autism over time.

\section{References}

Aldwin C. M. (I99I) Does age affect the stress and coping process? Implications of age differences in perceived control. Fournal of Gerontology 46, I74-80.

Bristol M. M. (1984) Family resources and successful adaptation to autistic children. In: The Effects of Autism on the Family (eds E. Schopler \& G. B. Mesibov), pp. 289-310. Plenum Press, New York.

Bristol M. M. (I987) Mothers of children with autism or communication disorders: successful adaptation and the double ABCX model. Fournal of Autism and Developmental Disorders 17, 469-86.

Bristol M. M., Gallagher J. J. \& Schopler E. (I988) Mothers and fathers of young developmentally disabled and nondisabled boys: adaptation and spousal support. Developmental Psychology 24, 44I-5I.

Bury M. (I99I) The sociology of chronic illness: a review of research and prospects. Sociology of Health and Illness I3, $45 \mathrm{I}-68$.

DeMeyer M. K. (1979) Parents and Children in Autism. V. H. Winston \& Sons, Washington, DC.

Erlandson D. A., Harris E. L., Skipper B. L. \& Allen S. D. (1993) Doing Naturalistic Inquiry. Sage, Newbury Park, CA

Gray D. E. (1994) Coping with autism: Stresses and strategies. Sociology of Health and Illness 16, 275-300.

Gray D. E. (2003) Gender and coping: the parents of children with high functioning autism. Social Science and Medicine 56, 63I-42.

Gray D. E. \& Holden W. J. (1992) Psycho-social well-being among the parents of children with autism. Australia and New Zealand fournal of Developmental Disabilities 18, 8393.

Hastings R. P., Kovshoff H., Brown T., Ward N. J., Espinosa F. D. \& Remington B. (2005) Coping strategies in mothers and fathers of preschool and school-age children with autism. Autism 9, 377-91.

Lazarus R. S. (1993) Coping theory and research: past, present, and future. Psychosomatic Medicine 55, 234-47.

Lazarus R. S. (1996) The role of coping in the emotions and how coping changes over the life course. In: Handbook of Emotion, Adult Development, and Aging (eds C. Magai \& S. H. McFadden), pp. 289-306. Academic Press, San Diego, CA.

Marcus L. (1977) Patterns of coping in families of psychotic children. American fournal of Orthopsychiatry 47, 383-99. 
D. E. Gray • Coping over time

Marcus L., Kunce L. J. \& Schopler E. (1997) Working with families. In: Handbook of Autism and Development Disorders, 2nd edn (eds D. J. Cohen \& F. R. Volkmar), pp. 63I-49. John Wiley \& Sons, New York.

Milgram N. A. \& Atzil M. (1988) Parenting stress in raising autistic children. Fournal of Autism and Developmental Disorders 18, 415-24.
Thoits P. A. (1995) Stress, coping and social support processes: Where are we? What next? Fournal of Health and Social Behaviour Extra Issue, 53-79.

Accepted 23 September 2006 